\title{
DE LA SECONDE BASE DE LA CONSTITUTION DE 1856 À LA RUPTURE DES RELATIONS DIPLOMATIQUES ENTRE L'ESPAGNE ET LE SAINT-SIÈGE
}

POR

\author{
BRIGITTE JOURNEAU
}

Argentina

\begin{abstract}
RESUMEN
Durante el bienio progresista (1854-56), las relaciones Jglesia-Estado dominaron la escena política. Interesan dos cuestiones: la «Unidad» católica de España, puesta en cuestión desde la segunda base de la nueva Constitución, y el proyecto de una nueva desamortización. El artículo está concebido como una continuación de otro anterior (Hispania Sacra, vol. XLIII, n. ${ }^{\circ} 88$ ) y analiza los discursos y enmiendas de la primera cuestión.
\end{abstract}

\begin{abstract}
During the progressive two-year period (1854-56), the Church-State relationships mastered the political scene. There were two important subjets: The catholic «Unity» of Spain put in question in the second Base of the new Constitution, and a new project for secularizing the real estate of the Church. The article is conceived as continuation from another one (Hispania Sacra, vol. XLIII, n. ${ }^{a}$ 8) and analyses the political speechs and amendments.
\end{abstract}

Lors du Bienio Progresista (1854-56), deux questions intéressant les relations entre l'Eglise et l'Etat dominèrent la scène parlementaire: celle de l'Unité catholique de l'Espagne mise en cause lors des longues discussions aux Cortès sur la seconde base de la nouvelle Constitution, qui durèrent du 13 janvier au 28 février 1855, et le projet d'une nouvelle desamortización annoncée à la fin de janvier de cette même année par Pascual Madoz.

La iglesia de los últimos siglos Hispania Sacra 50 (1998) 
L'article ici présenté est conçu comme étant la suite directe de celui précédemment publié dans Hispania sacra ${ }^{1}$. On y analysait les discours et amendements portant sur le premier point.

\section{PÉTITIONS DES ÉVÊQUES ADRESSÉES AUX CORTÈS}

On ne peut juger des discussions aux Cortès sur la seconde base sans tenir compte des exposiciones ou pétitions des évêques. La première en date est celle de l'évêque de Cadix, Juan José Arboli. Au cours de la séance du 29 janvier, après discussion, on décide de la liré2: l'évêque y attire l'attention sur l'ambiguïté du texte de la base dont les propagandistes des autres religions se prévaudront pour prêcher et célébrer leur culte. Il critique les termes de l'affirmation: «Los españoles profesan la religión del Estado», car, dit-il:

Si los españoles, como todos los hombres (...) deben profesar la verdadera religión, el Estado, esto es el Gobierno y los poderes públicos que rigen el país, no están menos obligados a esta profesión pública.

En conclusion, la profession de catholicisme des Espagnols n'est pas le fait de leur qualité d'Espagnols, mais l'obligation qu'ils ont comme tout homme de reconnaître la vérité, obligation qui atteint aussi l'État, et, sans qu'il le soit dit, pas seulement l'Etat espagnol. Le point de vue de l'évêque n'est pas celui des législateurs. Il part de la considération de l'absolu de la vérité, de ses droits, non de ceux de la nation, et c'est pour construire la société et pour édicter ses lois en accord avec la conception catholique du monde.

Si la base, ajoute-t-il, a voulu défendre la liberté de conscience, l'affirmation

que nadie podrá ser perseguido por sus opiniones mientras no las manifieste por actos públicos contrarios a la religión,

1 «a question de la liberté de culte et les débats aux Cortès en 1855», Hispania sacra, Vol. XLIII, n, ${ }^{\circ} 88$, pp. $475-502$.

2 Datée du 22 janvier 1855. Texte intégral dans D.S.C.C. (Diario de Sesiones de Cortes constifuyentes) Tome It. n. ${ }^{\circ}$ 70. pp. 1119-20. Séance du 29 janvier 1855 . La seconde base était rédigée ainsi: «La nación se obliga a mantener y proteger el culto y los ministros de la religión católica que profesan los españoles. Pero ningún cspañol ni extranjero podrá ser perseguido civilmente por sus opinjones mientras no las manifieste por actos públicos contrarios a la religión». Après le 10 février 1855, on supprimera le temc civilmente et on ajoutera, après "opiniones», “y creencias».

La iglesia de los últimos siglos

Hispania Sacra 50 (1998) 
est inutile, car tout le monde sait que les opinions ne peuvent jamais être soumises à laction des lois humaines, et c'est une maxime de la législation canonique de l'Eglise que de occultis non judicat Ecclesia. Quels seront ces actos públicos?

Toucheront-ils au domaine de l'enseignement? S'agit-il de répandre des doctrines contraires à la foi catholique? S'agit-il de commettre des délits contre le culte et la morale religieuse, ou d'empêcher le libre exercice de la religion catholique? Que les députés renoncent à la seconde base et adoptent à sa place l'article 12 de la Constitution de 1812 dans lequel on déclare pañoles,

ser la única verdadera, la religión católica, apostólica, romana que profesan los es-

et où l'on interdit l'exercice de tout autre culte ${ }^{3}$.

Les exposiciones des évêques vont se succéder. Elles demandent généralement que l'on retienne la formule:

la religión católica, apostólica, romana, es la sola exclusiva de la nación española.

Le 24 février, il en parvient une, signée par un grand nombre d'habitants de Jérez de la Frontera, présentant une requête identique. Quelques jours plus tard la municipalité de cette même ville en fait parvenir une autre mettant en cause la représentativité des signataires, ce qui entraîne une protestation de ceux-ci. C'est au moment où la base est sur le point d'être votée qu'affluent, après les pétitions des évêques, celles d'habitants de diverses localités, Burgo de Osma, Paredes de Nava, Carrión de los Condes, Avila, Valence. Le député Mascarós montre que tenir compte de celle des valenciens serait fausser la réalité. Que signifient 5000 signatures pour les 500000 habitants d'une province:

Y sobre todo, que no es la opinión de ninguna de las personas identificadas con la causa liberal lo prueba que algunos de los pocos nacionales que habían firmado esas exposiciones, después han retirado sus firmas, viendo que la opinión de toda la Milicia nacional les era contraria. Hay más, de cuatro batallones y dos escuadrones de Milicia nacional que tiene aquella capital, un solo oficial ha firmado la exposición y fué tal la opinión que se levantó contra él, que no pudiendo por sus compromisos retirar la firma que tenía

3 L'emploi des qualificatifs «apostólica» et «romana» sera réclamé par Jaén. Hispania sacra. ibid., p. 494.

La iglesia de los últimos siglos Hispania Sacra 50 (1998) 
puesta, se ha visto en la necesidad de renunciar el cargo de oficial, según cartas muy respetables que tengo en mi poder y de cuya exactitud respondo 4 .

Si Mascarós veut prouver qu'il ne faut pas tenir compte de ces pétitions parce qu'elles émaneraient de carlistes, on peut aussi bien en tirer la conclusion que la question est de toute façon politique, puisqu'on ne peut appartenir à la Milice nationale et être partisan de l'exclusivité de la religion catholique. S'il y a des pressions exercées par des curés, certaines exposiciones portant des listes de noms écrites d'une même main et pour seule signature celle de l'ecclésiasti$q^{2} e^{5}$, il y en a donc aussi de la part de la Milice et des milieux libéraux.

La base ayant été adoptée, on déclare aux Cortès qu'il ne faut plus tenir compte des pétitions. Mieux, dit Olózaga, ceux qui en envoient sont des rebelles:

\section{(...) porque repito que son exposiciones de rebeldes, $y ;$ ay de los rebeldes! ${ }^{6}$}

Au bas de la pétition de Valence, le député Sorni décèle des signatures de Jésuites; de là à penser qu'ils en sont les instigateurs, il n'y a qu'un pas. Il y a aussi des noms de délinquants:

El sacristán de San Camilo que por la sacristía robaba las gallinas del hospital general y fue sentenciado a presidio, es otro de los firmantes.

Voici, dit-il, quels sont les collaborateurs de son collègue Jaén! Il regrette que sa province de Valence ait été la première à donner l'exemple de pétitions adressées aux Cortès par des femmes. Ce n'est pas qu'il leur dénie ce droit, mais ce sont les Jésuites qui ont utilisé leur nom. Ces faits cités ont-ils été jugés convaincants?

L'étonnement devant l'intervention des femmes dans la politique, le spectre des Jésuites, et ce bagnard châtié par la justice rigoureuse du siècle rappellent au lecteur d'aujourd'hui que ce débat "périmé», s'inscrit dans un ensemble de convictions, de craintes, de phobies et de lois qui vont jusqu'à condamner à mort le vol. Cette rigueur dans la défense de la propriété, n'explique-t-elle pas, sans le justifier bien entendu, qu'on veuille sévir lorsqu'il s'agit de défendre les bases morales de la société?

\footnotetext{
4 D.S.C.C. Tome III. p. 1748. Séance du 3 mars 1855.

5 lbid.

6 Ibid.
}

La iglesia de los áltimos siglos

Hispania Sacra 50 (1998) 
Le 5 mars, Nocedal, Corvera, Moyano, le marquis d'Oviedo, Alejandro Castro, Jaén, Rancés et Villanueva, sollicitent des Cortès une déclaration en faveur du droit de tout Espagnol à adresser des pétitions sur tous les points qu'il jugera convenables pour le bon gouvernement du pays?

Cette proposition est repoussée par 143 voix contre 19, et l'on accueille par des bravos la remarque du ministre d'État, Luzuriaga:

Respecto de una ley que acaba de hacerse, la petición que contra ella se hace, no es un derecho practicado es un acto de sedicion.

Le 5 mars, c'est au tour du ministre de Gobernación d'ordonner:

(...) que no se hicieran exposiciones contra las bases aprobadas y que estuvieran a punto de aprobarse, advirtiendo expresamente que entregaría a los tribunales a todos aquellos que con tal motivo cometieran acciones penadas por la ley.

La question rebondira avec l'affaire de l'évêque d'Osma. Lors de la séance du 21 mars $^{8}$, on demande la lecture de la pétition qu'il a adressée trois semaines avant sur la desamortización. Ce qui motive cette demande, c'est le fait que El Católico dans son numéro du 16 mars l'ait publiée. Aguirre obtient que les Cortès la lui remettent en raison des termes irrévérencieux qu'elle contient à l'adresse du gouvernement et Escosura prononce un violent discours contre l'évêque. Celui-ci sera l'objet de poursuites judiciaires et devra obéir à un ordre d'exil. En réalité, l'irritation du gouvemement provenait de la menace d'excommunication contre les nouveaux acquéreurs de biens que contenait cette exposición.

Une certaine agitation persiste. Des opposants au régime, conservateurs ou carlistes, l'exploitent:

Los enemigos de las actuales instituciones (...) están concitando hace días los áni* mos contra las Cortes Constituyentes y contra el gobierno de S.M. haciendo cundir la voz de que se van a cerrar las iglesias y los conventos de monjas, que se va a abolir la religión católica, que se van a establecer sinagogas, que se va a tributar culto a Mahoma y otros absurdos semejantes: Hoy mismo me han asegurado algunos eclesiásticos que es tal el efecto que estas siniestras voces han producido en muchas personas, que se les han presentado compungidas o exaltadas por el temor de ver desaparecer la religión de sus

7 D.S.C.C. Tome III. nº 98. p. 1795. Séance du 5 mars 1855.

s D.S.C.C. Tome III. $\mathrm{n}^{\circ}$ 111. p. 2103. 
padres, y V.E. conoce los funestos resultados que en nuestro país puede producir esta alarma y la necesidad que hay de rectificar la opinión pública.

Cette lettre du gouverneur de la province de Murcie est adressée à l'évêque de Carthagène, le 12 mars, pour qu'il veuille bien inviter les ecclésiastiques de son diocèse à démentir du haut de la chaire ces calomnies et à calmer les esprits9. L'évêque voudrait bien, dit-il, tranquilliser les consciences, mais il ne le peut, n'étant pas lui-même exempt d'une certaine crainte:

Pero dispuesto siempre a buscar el bien por los medios racionales, lo estoy a firmar con Ud una exposicion al gobjerno de S.M. 0 a las mismas Cortes, suplicando con toda la sinceridad de los buenos españoles, de un gobemador y de un obispo que desean alejar de su país todo pretexlo más o menos fundado de alarma,suplicando se sirvan explicar los términos de la base en sentido capaz de aquietar las conciencias y disipar todas las dudas ${ }^{10}$.

Il y aura une nouvelle démarche du gouverneur et une nouvelle réponse dilatoire de l'évêque portée par le gouvemeur à la connaissance du ministre de la Justice qui paraît vouloir arrêter l'affaire.

Après avoir apporté ce complément aux débats parlementaires concernant la seconde base, il nous faut aborder les discussions aux Cortès concernant la désamortisation.

\section{LES DISCUSSIONS AUX CORTÈS. LA DESAMORTIZACIÓN}

La question de la desamortización entre dans une tradition qui se rattache aux réformes de Mendizábal. Les progressistes en font une affaire de parti comme de leur revendication en faveur de la tolérance des cultes, encore que sur ce point nombre de progressistes se soient montrés plutôt conservateurs. Il faut distinguer les progressistes avancés, proches des démocrates et des républicains, et les autres ${ }^{1 !}$.

? Archives du Ministère de la Justice (Madrid). Leg.4035.

10 lbid., 13 mai 1855.

"Dans un article «La política y la opinión pública en tomo a la desamortización de 1855» (Revista del Instituto de Ciencias sociales, Barcelona, 1973. n. ${ }^{\circ} 21$. pp. 93-154), Jarque Andrés analyse la poléntique parlementaire au sujet du projet de désarmortisation et la campagne de presse qui s'ensuit. Tout en soulignant le point d'honneur mis par les progressistes à faire aboutir les deux questions de la liberté des cultes el de la désamortisation, il n'établit pas de distinction entre les membres du parti progressiste. La vraie distinction à établir ne devrail-elle pas porter sur l'appartenance ou la non appartenance à la Franc-Maçonnerie?

La iglesia de los áltimos siglos

Hispania Sacra 50 (1998) 
Le projet de Madoz a une très grande ampleur. La desamortización doit avoir des incidences financières, créer une classe qui devra sa fortune au parti progressiste et renflouer les finances de l'État, mais elle implique une certaine attitude à l'égard de l'Église et l'on finira par justifier la vente des biens du clergé le mê'me que l'établissement d'une liberté des cultes, par la nécessité de construire des chemins de fer...

C'est vers la fin de décembre 1854 , que l'on commence à parler d'une désamortisation. Mariano Batllés présente une proposition de loi pour que l'on décrète la vente des biens de l'Église et qu'on interdise au clergé d'en acquérir à l'avenir $^{12}$. Elle est lue lors de la séance du 4 janvier $^{13}$. Il faut rompre le Concordat, dit Batllés, «el ominoso concordato», mais Aguirre, ministre de la Justice lui ayant assuré que le gouvernement préparait un vaste projet sur ces questions, Batllés retire sa proposition de loi.

Il revient à la charge le 22 janvier, après avoir été critiqué dans le journal La Verdad ${ }^{14}$ par un religieux, le P.Troncoso. On lui a dit que c'était un crime de dépouiller l'Église, mais l'Eglise, répond-il, n'est pas le clergé:

Si se entiende por Iglesia lo que debe entenderse, esto es, la congregación de todos los fieles cristianos, no se incurrirá en la indignación por quitar al clero los inmensos bienes para dárselos a la satisfacción de las necesidades públicas; y mucho menos cuando todo el mundo tiene hambre, y el gobiemo se ve destituido de los medios de aplacar este mal.

Le clergé est loin d'être l'Église, loin de suivre son esprit,

(...) la verdad única es la que está en el Evangelio, en las páginas de este libro sagrado, que es el primero que forma en línea de la lista de los libros prohibidos. Y qué diremos de un clero que llaman ellos Iglesia, cuya cabeza visible que es el Papa, pone como uno de los libros proljibidos, la Biblia santa la palabra de Dios escrita, esa palabra divina que todos debemos saber y observar 15 .

Batllés est un spécialiste des attaques contre le clergé, contre les évêques, particulièrement celui de Barcelone, Mgr Costa y Borrás, et contre le pape, et ces quelques lignes donnent le ton de ses discours. Cette desamortización qu'il justifie par sa conception d'une Eglise où le clergé n'a pas de place privilégiée, Pascual Madoz, qui vient d'être nommé ministre des Finances le 2I janvier,

12 D.S.C.C. 20 decembre 1854 . n. ${ }^{\circ} 39$. Appendice $2^{\circ}$,

3 D.S.C.C. Tome 1I. n. ${ }^{\circ}$ 50. p. 718.

$14 \mathrm{n}^{\circ}$ du 6 janvier 1855. Allusion à ces faits dans le $n^{\circ} 64$ du D.S.C.C. Sćance du 22 janvier 1855.

15. D.S.C.C. Tome II. $n^{\circ}$ 64. p. 1016. 
l'annonce trois jours après dans le premier discours qu'il prononce en cette qualité. Un tonnerre d'applaudissements accueille cette décision et le vote confirme cette approbation. Madoz met au point un projet qui est lu le 5 février aux Cortès:

Declarando en estado de venta los predios rústicos y urbanos, censos y foros pertenecientes al Estado, a los pueblos, al Clero y a los establecimientos y corporaciones de beneficencia e instrucción públical6.

Il s'agissait donc d'une vaste entreprise de désamortissement, qui ne touchait pas que les biens du clergé, mais qui atteignait aussi les biens de main morte civile. Une commission ${ }^{17}$ est ensuite chargée d'une étude approfondie, et livre aux Cortès, le 23 février, une proposition de loi plus élaborée ${ }^{18}$ :

La ley propuesta es una revolución fundamental en la manera de ser de la nación española; es el golpe de muerte dado al antiguo y deplorable régimen; es en fin, la fómula y resumen de la regeneración política de nuestra patria.

On se défend cependant de dépouiller les propriétaires de main morte; on ne change que la forme de cette propriété. Pour les biens du clergé, on prétend que leur vente est en accord avec ce qui a été stipulé dans l'article 35 du Concordat, et que d'ailleurs, en raison d'utilité publique, elle aurait pu être décidée même si cet article n'existait pas.

La commission en fausse l'interprétation, comme on le verra dans les documents de la correspondance diplomatique. Le projet de loi précise qu'il sera interdit aux mains-mortes à l'avenir d'acquérir des biens fonds. Il s'agit de créer une situation irréversible. Non seulement doivent disparaître les biens des deux clergés, c'est-à-dire séculier et régulier, mais aussi les rentes, les cens (censos) et les commanderies (encomiendas) qui avaient été réunies à la dotation du clergé séculier.

Aussitôt, une campagne de presse se déclenche. Tandis que les journaux progressistes montrent les bienfaits à attendre de la desamortización, notam-

16 D.S.C.C. $\mathrm{n}^{\circ} 76.5$ février 1855 . Appendice.

17 Présidée par Antonio González, ayant pour secrétaire Patricio de la Escosura, elle se compose de José Cristóbal Sorní, Paciano Masadas, José Gálvez Cañero, Fernando Madoz, Manuel Fuente Andrés (cf. SIMÓN SEGURA, FRANCISCO, La desamortización española del siglo XIX. Instituto de Estudios fiscales. Ministerio de Hacienda).

18 Dictamen de la Comisión sobre el Proyecto de Ley para la Desamortización general de los bienes de manos muertas, et texte du projet de loi en appendice, pp.301-28.

La iglesia de los últimos siglos Hispania Sacra 50 (1998) 
ment la mise en valeur de terres par le passage de la propriété collective à la

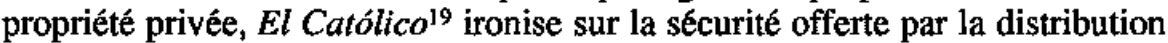
de bons à $3 \%$.

Comment l'Etat aura-t-il des fonds suffisants pour assurer le versement régulier de cet intérêt alors que les acheteurs de biens auront quatorze ans pour effectuer leur paiement?

Quant à La Epoca, journal modéré, il critique le préambule de la loi, en accusant les progressistes de s'attribuer le mérite d'avoir procédé aux précédentes desamortización, et de vouloir faire oeuvre de parti. La loi pour être efficace doit être l'expression de la volonté nationale ${ }^{20}$. Par la suite il exprimera des idées en faveur d'une desamortización progressive et tempérée, bref conduite autrement que par les progressistes.

A partir du 1 er mars, arrivent des pétitions d'évêques au sujet de la vente des biens du clergé. Elles succèdent à cèlles adressées aux Cortès contre la seconde base.

La discussion sur le projet de loi qui durera jusqu'à la fin du mois d'avril, commence le 26 mars. La question de la desamortización ecclésiastique sera parfois dépendante, parfois dissociée de celle de la désamortisation dans son ensemble.

Le premier discours, celui de Claudio Moyano, au nom des conservateurs, s'oppose à la totalité du projet, économiquement préjudiciable aux corporations qui en sont l'objet et aux populations laborieuses des campagnes. Faire disparaitre le droit de propriété du clergé, celui des communes, ce sera mettre en péril celui des particuliers, faire tomber les derniers bastions qui le protègent. Moyano met en cause la compétence des Cortès pour prendre une telle décision sans l'assentiment des intéressés. Ses arguments sont réfutés d'abord par Patricio de la Escosura, au nom des progressistes. Il justifie tout par l'intérêt général et ne s'embarrasse pas du Concordat:

El Concordato es un sello de infamia puesto a la revolución española por las manos de los que lo firmaron'21.

Mais Aguirre précise que ces ventes peuvent avoir lieu sans que l'on soit en désaccord avec les dispositions du Concordat, attitude qui sera constamment celle du gouvernement, tandis qu'Antonio González, président de la commis-

196 février 1855 (JARQUE ANDRÉS, op. cii., p. 110)

2024 février 1855 , Ibid., p. 117.

21 Simón SEGURA, op. cit., p. 172. 
sion $^{22}$, invoque le dominio eminente de la nation sur la propriété existant dans le pays.

Madoz, enfin, dans un brillant discours, défend le droit des Cortès à légiférer et énumère les avantages que toutes les catégories sociales devraient retirer de sa loi.

La question est politique et donne lieu à des affrontements aux Cortès où chacun déploie ses arguments sans tenir compte de ceux des autres.

Pour les progressistes, la desamortización est considérée comme une réforme considérable, l'oeuvre de la révolution et la garantie du nouvel ordre régnant, l'aboutissement de celle commencée par Mendizábal, le moyen de combler le déficit de l'État, de lui permettre d'entreprendre de grands travaux d'intérêt public et de développer l'agriculture.

Pour les conservateurs, auxquels se joignent quelques progressistes comme Jaén, il s'agit aussi d'une affaire de première importance, mais qu'ils jugent désastreuse, souvent dans son principe, toujours dans ses conséquences. Menée avec précipitation, elle appauvrira à la fois la nation et les intéressés, à l'exemple de celle de Mendizábal. Centralisant à outrance, elle multipliera les catégories sociales dépendantes de l'Etat pour leur subsistance, et les mécontents quand les caisses seront vides comme il faut s'y attendre. Elle ne favorisera que les spéculateurs.

La plupart des amendements proposés concernent les bienes de propios au sujet desquels affluent les pétitions provenant des municipalités, mais de nombreuses interventions auront lieu aussi au sujet des biens du clergé. Sans cesse Madoz, Escosura et Antonio González essayeront d'accélérer le débat.

Dans la presse, les mêmes affrontements ont lieu. El Católico, dans six articles publiés du 10 mars au 19 mars, insiste sur le caractère sacré de la propriété, nie qu'il existe une différence entre propriété collective et propriété individuelle, souligne l'échec des desamortizaciones précédentes qui ont enrichi quelques capitalistes au détriment des fermiers ou métayers dont les baux ont été augmentés, tandis que les anciens propriétaires étaient réduits à emprunter pour vivre et, comme l'avait fait Moyano, avertit la nouvelle classe possédante du danger qu'il y aurait à saper le droit de propriété de l'Église, donc à travers lui le droit à toute propriété ce qui pourrait bien se retourner contre elle un jour ${ }^{23}$. «Enreurs et périls imaginaires» rétorquera la presse progressiste.

Le 16 mars, El Católico publiera la pétition de l'évêque d'Osma adressée aux Cortès le 1 er mars et qui irritera tant le gouvernement:

2211 fut président du Conseil des ministres en 1841 et avait alors proposé de déclarer biens nationaux tous les biens du clergé.

23. Cf. JARQUE ANDRÉS, op. cit., pp. 131-7. 
Se dará lugar a que los centinelas avanzados de la Casa de Israel, en cumplimiento de su espinoso ministerio y obedeciendo a la que se dispone en las sagrados canones, con especialidad en los concilios generales de Constanza, sesión octava contra Wiclef; el de Trento, sesión 22, cap.II, De Reformatione, y multitud de Bulas pontificias, señaladamente la de In Coena Domini; se dará lugar a que los obispos esgriman esta espiritual espada contra los violadores de la Iegislación divina, contra los usurpadores de los bienes de la Iglesia, declarándoles separados de la comunión de los fieles como miembros podridos, privados de la entrada en el templo, de la participación de los sacramentos y de sepultura eclesiástica en la hora de la muerte ${ }^{24}$.

Cette menace des peines spirituelles que l'Église peut imposer à ceux qui mettent en oeuvre la desamortización des biens du clergé et aux nouveaux acquéreurs de ceux-ci, en recouvre une autre, s'appliquant aux anciens acquéreurs qui jouissaient maintenant pacifiquement de leurs biens, et qui aurait effet si les députés votaient ce projet:

(...) cuyas tendencias nada tienen de católicas, que es también antisocial, porque barrena y destruye la propiedad y la justicia, sin las cuales no puede existir, ni aun concebirse, la sociedad, y que además dejaría mal paradas a las que en la revolución pasada se apoderaron de los bienes de la Iglesia, y que sólo han hecho suyos en virtud del tantas veces citado último Concordato, cuyas principales bases se destruyen por el presente proyecto de desamortización eclesiástica ${ }^{25}$.

L'évêque d'Osma paiera d'un exil la violence de ton de cette exposición, mais c'est bien sur les principes traditionnels de l'Eglise qu'il se fonde. Il ne peut que s'opposer à ceux qui fondent le droit sur l'intérêt de la nation et la souveraineté nationale.

Le 27 mars, Corradi, approuvant et commentant dans El Clamor público la réponse apportée par Escosura à Moyano, dira:

Es ciertamente una verdadera aberración, si es que no una temeridad maliciosa empeñarse en desconocer la facultad que tiene la Nación hasta para expropiar de sus bienes a los particulares o corporaciones cuando el interés general del país la reclama, como sucede con la desamortización de los bienes llamados del clero, que en realidad no son sino del Estado ${ }^{26}$.

24 Ibid., p. 137. Il es1 à remarquer que l'emploi du terme «espiritual espada» s'explique comme une reférence indirecte á la teoria de las dos espadas, ces deux épeés qui représentent, l'une le pouvoir spirituel, l'autre le pouvoir temporcl. En établissan entre ces deux pouvoirs une distinction, l'évêque d'Osma est parfaitement en accord avec l'interprétation la plus favorable au pouvoir temporel de l'Étal.

25 Argument que reprendra Moyano lors de la séance du 28 mars (D.S.C.C. $n^{\circ} 117$ ).

26 JARQUE ANDRÉS, op, cit, p. 141. 
La plupart des évêques, s'adressant aux Cortès, adoptent un ton plus courtois, ou plutôt moins menaçant que l'évêque d'Osma, mais emploient à peu près les mêmes arguments. Pour l'évêque de Carthagène ${ }^{27}$, les trois bases de la société sont la religion, la justice et la propriété. Tout ce qui atteint la propriété atteint la justice et la religion. Attaquer une forme de la propriété, c'est attaquer toutes les autres. La dernière desamortización a appauvri le peuple. La théorie selon laquelle la nation peut disposer à son gré des biens d'Eglise est du point de vue de la religion catholique une erreur constamment condamnée. Les évêques sont d'accord avec les mesures prises, si l'Etat obtient auparavant l'autorisation du Saint-Siège. Il ajoute cette remarque: il serait même de leur intérêt de voir vendre les biens qui leur ont été rendus; dans son propre diocèse, ils représentent une lourde charge.

Cette exposición, imprimée et répandue à profusion dans la province, est transmise au ministre de Gobernación, par le gouverneur de Murcie en quête d'ordre sur la conduite à suivre devant ce fait propre à créer des conflits avec l'autorité:

Bien penetrado de sus intenciones hostiles había pensado recoger todos los ejemplares que ya se han repartido, ateniéndome al espíritu del artículo 304 del Código penal,

mais selon les juges de première instance la saisie ne peut avoir lieu:

por no estar aun aprobado el proyecto de desamortización a que este Prejado se contrahe....28.

La loi de désamortisation fut votée article pour article, et la dernière clause, approuvée le 27 avril. Il s'agissait d'obtenir ensuite la sanction de la reine qu'elie donna contrainte et forcée. On avait frôlé le pire: son refus qui aurait pu lui coûter son trône ou donner lieu à un soulèvement. La loi, connue sous le nom de loi Madoz, fut publiée le 1 er mai.

${ }^{27}$ Exposición dirigida a las Cortes Constituyentes, por el exmo é ilmo Sr. Dr. Don Mariano Bario Fernández, obispo de Cartagena y Murcia sobre El proyecto de Ley de desamortización de los bienes de la Iglesia, Beneficencia, Instrucción pública, etc. Mutcia, impr. de Pablo Nogués, 1855.

28 Archivo histórico nacional. Leg. 11317(1), 24 mars 1855.

La iglesia de los últimos siglos

Hispania Sacra 50 (1998) 


\section{L'APPLICATION DE LA LOI}

Il s'agissait maintenant d'appliquer la loi. On créa le 15 mai, la Dirección general de Ventas de Bienes nacionales. Le directeur général dépendait directement du ministère des Finances. Une instruction donnée par Madoz, le 31 mai, précisait ses attributions et celles des différents fonctionnaires de cette administration, au premier rang desquels on trouvait les comisionados principales, chargés dans chaque province de rechercher et de vendre tous les biens désignés par la loi Madoz et d'administrer les biens du clergé. Ils se trouvaient être sous la dépendance à la fois de la Direction générale et des gouverneurs civils et travaillaient en accord avec ces demiers ${ }^{29}$. Ils devaient dresser les inventaires des biens et les remettre à la Direction, déposer chaque mois à la Trésorerie les sommes perçues en espèces.Ils pouvaient mettre les biens en location ou arrêter les baux, et dresser les devis des travaux à effectuer. Ils touchaient comme rétribution $3 \%$ sur les sommes versées à la Trésorerie provenant du partido de la capital, et $0,25 \%$ sur le produit des ventes. Chaque comisionado principal nommait des comisionados subalternes qui se trouvaient être à leurs ordres et qui touchaient $3 \%$ sur les sommes en espèces versées au Trésor provenant du district dont ils avaient la charge.

Il y avait aussi des investigadores ayant pour mission de repérer les propriétés ou les cens, dont les possesseurs dissimulaient l'existence, en faisant des recherches dans les archives civiles et ecclésiastiques. Ils devaient ensuite transmettre le résultat de leur enquête aux comisionados principales. Ils étaient rémunérés en fonction des biens découverts.

Dans chaque province, il y avait des contadores ou chefs de comptabilité pour dresser les états des ventes, surveiller les enchères et la conduite des comisionados et des investigadores. A l'intérieur de la Direction générale, il fallut créer une Junta superior de ventas, et dans chaque province une Junta provincial de ventas en dépendente d'elle ${ }^{30}$.

La désamortisation allait demander le concours d'un grand nombre d'autres personnes, experts, géomètres, architectes, juges de première instance et greffiers.

La liste des biens passés au pouvoir de l'Etat et mis en vente était publiée dans le Boletín oficial de Ventas de Bienes Nacionales. Un décret royal du 16 avril 1856 devait créer une Administración de Bienes nacionales dépendante de la Dirección general de Ventas.

29 STiGURA, SimÓN, op. cit, pp. 200-3.

to SEGURA, Simón, op. cit., p. 204. 
Ces fonctionnaires vont te se heurter souvent à la résistance passive des évêques. Les inventaires que possède le ministère des Finances étant incomplets, il faut qu'il se procure les archives du clergé. Les évêques, en général, ne voudront ni les lui fournir, ni inviter les ecclésiastiques à le faire.

L'évêque de Zamora est le premier à expliquer son attitude ${ }^{31}$ : il ne peut en conscience, sans l'approbation du pape, livrer le patrimoine de l'Eglise dont il est le gardien. Agir autrement le rendrait gravement coupable selon la législation canonique. Les conciles, ceux de Tolède, celui de Trente particulièrement ${ }^{32}$, et les brefs du pape, condamnent formellement un tel abandon. C'est bien d'une résistance passive qu'il s'agit:

Mi conciencia no me permite complacerle disponiendo que mis subordinados faciliten las noticias que se reclaman; antes bien debo reproducir la protesta que tengo hecha con mis hermanos del episcopado, y en nuestro caso imitar el ejemplo de San Ambrosio que decía: «Si el Emperađor quiere las tierras, tómelas si le place. No las doy pero tampoco resisto...: Si pide lo que es mío, no contradeciré; pero las cosas de Dios, no están bajo la potestad imperial: si pedís el patrimonio, invadidlo.»

Le gouverneur civil auquel cette opposition s'est manifestée s'inquiète; il craint un complot et en avertit le gouvernement:

Las máximas altamente perniciosas y alarmantes en que abunda la adjunta comunicación hacen de ella un asunto harto grave que debe ser tratado seriamente por el gobierno de S.M. bien informado de los proyectos y tendencia al parecer organizada de quienes provocan a la acción en todos los terrenos ${ }^{33}$.

Mais faudra-t-il en venir à l'épreuve de force? D'autres évêques répondent plus brièvement en invoquant le concile de Trente et le serment qu'ils ont fait lors de leur consécration épiscopale ${ }^{34}$. Celui d'Avila fait remarquer ${ }^{35}$ que l'Etat a les renseignements nécessaires dans les Archives du ministère des finances, renseignements qui datent du temps où l'on avait rendu ces biens au clergé.

31 Archivo Histórico Nacional. Sección de Hacienda. Clero secular. Incautaciones. Leg. 373. Expediente general sobre la resistencia pasiva que presentan los obispos al cumplimiento de la ley de desamortización. Lettre au gouverneur civil de la province. 14 juin 1855 .

32 Session 22, chapitre 11

33 Lettre du 18 juin 1855 , adressée au directeur général des Ventes et transmise au ministre des Finances le 21 juin.

34 Ibid. Lettre de l'évêque de Salamanque. 26 juin 1855.

35 lbid. Lettre au gouvemeur civil. 27 juin 1855.

La iglesia de los últimos siglos

Hispania Sacra 50 (1998) 
Les gouverneurs craignent que ces exemples de désobéissance aux lois n'entraînent des réactions anarchiques chez les simples citoyens. Celui de Valence essaye de convaincre l'archevêque de cette ville ${ }^{36}$ : la desamortización le déchargera du souci d'administrer des terres, lui faisant ainsi gagner un temps précieux pour la prédication. Celuí de Cáceres est décidé à sévir contre l'évêque de Plasencia ${ }^{37}$. Il lui intime l'ordre de se rendre dans les quarante-huit heures à Madrid pour y recevoir les instructions du gouvemement.

La controverse est parfois virulente. Le gouvemeur de Salamanque est en conflit avec le chapitre de la Real Capilla de San Marcos qui refuse de remettre les documents réclamés. Il en tance vertement le doyen:

Si Ud no estubiera acostumbrado al estilo de los ominosos tiempos de Torquemada y de la nunca bastante execrable Inquisición, no se hubiera atrebido nunca a dirigirse en términos tan inconvenientes e irreverentes a la primera Autoridad de la Provincia representante de S.M. la Reina constitucional de España Doña Isabel II (q.D.g.) a la que siempre se debe acudir con el mayor respeto y beneración y protestando la mayor sumisión y acatamiento a sus órdenes y mandatos. Este es el primer deber de todo súbdito español y el más obligatorio aun para los sacerdotes y ministros del Señor, que son los más estrechamente obligados a dar ejemplo de obediencia y mansedumbre y no de orgullo y de soberbia, poniéndose a disputar de igual a igual y sin fundadas razones con sus superiores por todos conceptos, como es primera Autoridad de la Provincia que ejerzo en nombre de S.M...

Por último prevengo a Ud que en lo sucesivo cuando se propase a resistir las órdenes superiores... consulte sobre todo autor las Leyes y ordenes que se proponga a impugnar para no dejar a descubierto su supina ignorancia sobre ellos como sucede ahora ${ }^{38}$.

Le refus, quoique ferme, avait pourtant été exprimé en termes courtois. Certains prélats, en termes mesurés, essayent d'expliquer leur position de principe, par le fait qu'un chrétien et à plus forte raison un ecclésiastique doit obéir à deux autorités.

L'archevêque de Compostelle s'adresse ainsi au gouverneur de La Coruña, Juan Gutiérrez:

En rigor, el conflicto no lo hemos creado ninguno de los dos: Dios es cierto que prescribe obedecer a las autoridades de la tierra. Así lo he enseñado y así lo enseñaré siempre; pero al mismo tiempo que manda dar al César lo que es del César, manda también dar a Dios lo que es de Dios, lo que quiere decir que un católico tiene que reconocer dos autoridades supremas cada una en su esfera, y lo que desgraciadamente nos divide es la apreciación de la esfera a que pertenece el asunto de que se trata: aunque no

36 Ibid. Lettre du 6 juillet à l'archevêque.

37 bid. 26 juin 1855.

38 Salamanque, 11 juillet 1855 . Ibid. Leg. 373. 
negaré que pueda haber algún simple fiel que conozca la ley de Dios tanto o más que un obispo, nunca concederé que tenga autoridad para enseñarla o interpretarla auténticamente como un obispo.

Il n'est que de se référer au Nouveau Testamen ${ }^{39}$ pour avoir l'explication de sa conduite: tout vient d'une différence d'appréciation, et non d'un désir de provoquer des troubles pour renverser le gouvernement.

Le gouvemeur n'en est pas persuadé pour autant. Dans une lettre confidentielle au ministre des Finances ${ }^{40}$, il parle de conjuration, unique explication selon lui de cette attitude d'opposition générale et systématique. Dans l'attente des directives sur les dispositions à prendre à l'égard du prélat, il a jugé bon d'essayer de convaincre d'abord les autorités secondaires: le prieur de la collégiale sera le premier invité à transmettre les documents qu'il possède. En cas de refus, on engagera des poursuites contre lui devant le tribunal de première instance.

Pour mettre en route la desamortización, le directeur général des ventes propose que les gouverneurs, à la demande des comisionados provinciales de ventas, fassent procéder par des experts compétents à l'identification des propriétés du clergé, à leur délimitation et à leur mesure, afin de combler les lacunes existant dans les inventaires des ministères.

Au début de juillet, ordre est donné de mettre la loi en application. A Tolède, pour vaincre l'opposition de l'administrateur diocésain, D.Diego Maza, obéissant aux ordres du cardinal Bonel y Orbe, on lui adresse, le 10 juillet, une sommation par l'intermédiaire du comisionado de ventas et d'un greffier. On se contentera d'un geste symbolique:

Le indicaron señalase une finca de que pudieran tomar posesión a nombre de las demás, verificado lo cual en una casa se tomó de ella, quieta y pacífica posesión a nombre de todos los bienes de aquel clero y se levantó de todo diligencia formal.

L'honneur était sauf, et le gouvemeur reçut des félicitations de Madrid ${ }^{41}$. Celui d'Avila,disposé à agir rapidement, convoque les deux administrateurs des biens du clergé de cette ville, Pío del Castillo y Gayangos et Pedro Moyano, et les somme de présenter dans les vingt-quatre heures les listes demandées, mais en vain:

\footnotetext{
39 Mathieu. 28 (verset I, et 20). Actes des Apôtres. Chapitre IV,

40 Ibid. Leg. 373.15 juillet 1855 .
}

41 Archivo Histórico Nacional. Sección de Hacienda. Leg. 373. 
Contestaron que en la misma forma que el R.obispo y bajo la protesta de que reconocían y acataban las disposiciones de los poderes legítimos y de la Autoridad que les invitaba, no podían de manera alguna cooperar a la ejecución de la ley, bajo cuyo concepto creían un deber de conciencia negarse como se negaban a formar las expresadas relaciones cuyos documentos bajo ningún pretexto se prestarian a autorizar con sus firmas ${ }^{42}$.

Devant tant d'obstination, le gouverneur veut porter l'affaire devant le tribunal de première instance.

A Barcelone, on utilise le même procédé qu'à Tolède: on prend possession d'une maison à titre symbolique, mais de plus on s'empare des archives ${ }^{43}$. Ceci est conforme à l'ordre royal publié le jour-même, le 19 juillet. Il ordonne de dresser procès-verbal en cas de refus des évêques et de procéder à la confiscation des biens, en se référant aux inventaires ayant servi en 1845, 1849 et 1851 , et se trouvant normalement à la délégation des Finances de la province. Accompagné du juge de première instance, le gouverneur devait prendre possession effective au nom de toutes les autres d'une des propriétés signalées dans ces inventaires. A partir de ce moment-là, on considérerait comme réalisée comme de droit la confiscation des biens et l'on en avertirait les maires par le bulletin officiel, afin que les loyers ou les cens ne soient plus perçus par les administrateurs diocésains.

Les maires avaient huit jours pour fournir la liste de tous les biens du clergé se trouvant sur leur territoire et de tous les cens payés par les habitants du village. Ils devaient obliger sous peine d'amende les fermiers ou locataires à signaler les propriétés qu'ils louaient et à donner tous les renseignements les concernant. Ces listes seraient confrontées aux documents primitifs et l'on procéderait immédiatement à la vente des biens. Ceux qui auraient des droits à faire valoir, tels que charges ou prestations, disposeraient de trente jours pour se faire connaître.

On s'était aperçu que la plupart des propriétés ne pouvaient pas être vendues dans l'ignorance où l'on était des charges qui les grevaient et qu'il fallait auparavant liquider. Les documents de l'Etat ne les signalant pas, il fallait s'emparer coûte que coute des archives du clergé où étaient conservés les titres primitifs de propriétét4. Les gouverneurs y étaient autorisés et même invités par ledit décret. Ils s'en emparèrent donc dans plusieurs régions, Zamora, provinces basques, Tarragone, à partir de cette date. A León, à Astorga, les inventaires leur furent remis sans résistance. En quelques endroits, ils n'exis-

\footnotetext{
42 Ibid.

43. Ibid.

44 Lettre du directeur de la Dirección general de ventas de bienes nacionales au ministre des Finances. 16 juillet 1855 .
} 
taient plus. L'évêque de Lérida, Pedro Cirilo Uriz y Labayru ${ }^{45}$ en donne les raisons propres à sa région et à l'Aragon. Dans son diocèse, dans les premiers jours de la révolution de juillet, les archives de quarante-deux paroisses avaient été brûlées sur les places par des personnes qui justement payaient des cens. Comment les prêtres pourraient-ils reconstituer de mémoire la liste des biens? Par ailleurs, ils avaient été insultés à l'époque. Ce serait s'exposer à la vindicte publique que de désigner ceux qui payaient les cens et qui se trouvaient être les responsables de l'auto-da-fé des registres en 1854 .

Des protestations parviennent aussi au sujet des récoltes. On est en juillet. Est-il normal qu'on les attribue à ceux qui n'ont rien semé? L'archevêque de St Jacques fait remarquer qu'en Galice, une partie des biens du clergé n'est pas donnée en location mais cultivée par les curés eux-mêmes. Ils vont se voir frustrés du fruit de leur travail, ce qui est d'autant plus injuste que certains de ces revenus pris en compte couvraient le retard de paiement de la dotation de 1854.

Les évêques font par ailleurs part de leur étonnement de ne pas avoir reçu directement des ordres du gouvernement et de n'avoir été mis au courant que par les gouverneurs. Ils font aussi remarquer que la loi ne précisait pas que les évêques dussent intervenir.

Enfin, il y eut des cas où l'ordinaire du lieu, ayant finalement autorisé les curés à fournir les rapports demandés, certains s'y refusèrent, comme le curé de Valdeobispo, du diocèse de Cáceres. Le gouverneur voulait le faire punir par son évêque, mais il finit par le traduire devant un tribunal de première instance et obtint sa rétractation ${ }^{46}$. D'autres ecclésiastiques sont critiqués, pour avoir dans leurs sermons, attaqué la loi de desamortización ${ }^{47}$. La résistance de certains est parfois un prétexte pour se faire pardonner la lenteur avec laquelle les opérations sont menées.

C'est ainsi qu'après avoir opposé un refus, le gouvemeur ecclésiastique de Villafranca del Bierzo avait fini par remettre les clefs des archives; le juge de première instance y saisit quatorze liasses de documents. Cinq mois passèrent. Le commissaire aux ventes n'avait toujours pas dressé l'inventaire, mais étaitce la faute du gouverneur ecclésiastique dénoncé au gouvernement ${ }^{48}$ ?

Pour apprécier à leur juste mesure les craintes des gouverneurs civils et leur attitude, il faut tenir compte de ce que l'on redoute en mai, après la sanction de

${ }^{45}$ Ibid. Leg. 373. 5 juillet 1855.

46 Ibid.

47 C'est ce que La lberia, $\mathrm{n}^{\circ} 149$, du 7 août 1855, dit des curés des villages voisins de La Junquera (province de Gerone), et le Diario Español, $n^{\circ} 1013$, du 3 octobre 1855, de l'aumônier des rcligicuses de Canillejas (province de Madrid).

48 Archives du ministère de la Justice. Leg. 4032. Lettre du gouverneur ecclésiastique à la reine, 29 décembre 1855.

La iglesia de los últimos siglos Hispania Sacra 50 (1998) 
la loi par la reine, une recrudescence du carlisme. En effet, un soulèvement se produit à Saragosse, les 22 et 23 mai. Il semble cependant que dans tout le pays, les autorités civiles, ministres et gouverneurs, des progressistes mis en place par la révolution de juillet, aient tendance à surestimer le danger et à considérer comme l'expression de convictions carlistes tout refus des ecclésiastiques d'obtempérer à leurs ordres.

Aguirre, par une circulaire du 27 mai, ordonne aux évêques de destituer les vicaires et de déplacer les curés que l'on pourrait supposer favorables au carlisme. On pourrait craindre une vaste épuration, mais l'instruction du 29 mai est plus restrictive:

Es la voluntad de S.M. que U. disponga cesen en la regencia de los curatos de que están encargados les ecónomos que hayan estado en el campo carlista, y los que durante la gucrra se hubieren ordenado en el extranjero, eludiendo los preceptos del Gobiemo que prohibían por entonces la admisión a las ordenes sagradas, y sean designados como peligrosos por las Autoridades civiles; y que muden temporalmente de residencia los curas propios que se encuentren en cualquiera de estos $\operatorname{casos}^{49}$.

11 ne doit donc s'agir que de cas particuliers ${ }^{50}$. Mais la première circulaire avait jeté l'inquiétude dans le clergé. L'évêque d'Orihuela, répondant à la circulaire du 27 mai, se demande s'il ne doit pas abandonner son diocèse:

Si bien el Obispo que expone no está comprendido en lo literal de ella, cree estarlo en su espíritu, pues que estuvo en dicho campo. Pero sea de esto lo que quiera, y que el exponente está por la misericordia de Dios infinitamente distante de todo pensamiento, palabra y obra que no sea de paz y de obediencia a V.M. $y$ al gobiemo que rige la Nación, se cree estrechamente obligado a llevar to dicho al soberano conocimiento de V.M. para que se digne resolver lo que fuere de su Real agrado sobre su permanencia o no permanencia en su Diócesis ${ }^{51}$.

Louant son abnégation, la reine lui demandera de rester ${ }^{52}$. Tandis que certains gouverneurs se plaignent de l'activité du clergé en liaison avec l'aristo-

\footnotetext{
49 Archives du ministère de la Justicc. Leg. 4012, $\mathrm{n}^{\circ} 20945$.

so Il semble qu'Aguirre ail agi seul, sans prendre l'avis de ses colleggues du gouvernement. Pour révoquer la mesure sans avoir à se dêjuger, Aguirre prétendit qu'il y avail eu une erreur de rédaction de la part des employés du ministère et que dans la phrase: «Cesen en la regencia de los curatos los ecónomos que hayan estado en el campo carlista, los que se hubiesen ordenado en el extranjero y todos los que sean designados como peligrosos», il fallait supprimer «todos los que», et lire, «y sean designados...». Ainsi, sculs étaient mis en cause ceux qui auraient pu porter préjudice à l'ordre public.

s1 lbid. 30 mai 1855

\$2 lbid. 4 juin 1855 .
} 
cratie et le parti polaco ${ }^{53}$, la pastorale adressée le 31 mai à ses diocésains par l'archevêque de Saragosse, D.Manuel María Gómez de las Rivas, est citée en exemple par le gouvernement, insérée dans la Gaceta du 6 juin, et objet d'une circulaire adressée aux gouverneurs ${ }^{54}$ leur ordonnant de la publier dans le $\mathrm{Bu}$ lletin officiel de leur province:

(...) para que los pueblos conozcan que, no ya los delegados del Gobiemo, sino los Pastores mismos de la Iglesia, que los enemigos del Trono y las instituciones suponen perseguida, aconsejan la sumisión y reconocen la legitimidad de los poderes públicos.

L'évêque, dans sa pastorale, avait insisté sur la soumission due au gouvernement et engagé le clergé à prêcher constamment l'union et la fraternité.

Les évêques ne transmettent pas, bien entendu, de listes d'ecclésiastiques ayant appartenu au parti carliste comme on le leur demande. Ils répondent qu'ils ne connaissent pas de cas semblables. A Tolède, pour combler cette lacune, le gouverneur croit bon d'envoyer les noms de ceux qui, pendant la dernière guerre civile ont aidé le parti carliste et qui exercent encore une influence, en tout onze personnes ${ }^{55}$ dont plusieurs appartiennent au chapitre de la cathédrale. Certains sont proches parents de carlistes connus, plusieurs ont milité dans l'armée carliste une vingtaine đ'années plus tôt. Les rapports ont été fournis par les commandants de la milice nationale et le comisario de protección y vigilancia pública de la ville.

De telles enquêtes devaient porter sur plus d'un cas puisqu'il existe des imprimés tout prêts de la section des Affaires ecclésiastiques du ministère de la Justice:

S.M. la Reine se ha servido mandar que informe V.Ema. sobre la conducta moral y política de...56

Mais il est possible que ces imprimés aient servi en d'autres circonstances, par exemple à des enquêtes de moralité en vue de nominations ou de promotions.

Ce seront les gouverneurs qui, de temps en temps, dénonceront des factieux: un prêtre du diocèse de Lugo qui, dans un sermon, a menacé d'excommunica-

53 Lettre du geouverneur des Baléares, 21 juin 1855. Ibid.

54 Archives du ministêre de la Justice. Leg. 4038. 11 juin 1855.

ss Une autre liste en compte quatorze (Archives du ministère de la Justice. Leg. 1012. $\mathbf{n}^{\circ}$ 20945).

5t Ainsi demande-t-on à l'archevêque de Tolêde ce qu'il pense de la conduite du curé de Villapalacios (21 đécembre 1855). La réponse esı qu'elle est bonne (Archives de l'Archevêché de Tolèđe. Leg. Bonel y Orbe: $n^{\circ} 9$. Affo 1855).

La iglesia de los últimos siglos

Hispania Sacra 50 (1998) 
tion les acheteurs de biens nationaux, est emprisonné sur ordre du gouverneur civili $^{57}$, mais au ministère de la Justice, on estime qu'on ne peut punir sur le seul témoignage de trois personnes assistant à la messe ce jour-là.

Le gouverneur de Lugo est assurément très zélé: il fait saisir une pastorale adressée par l'évêque à ses diocésains, le 1 er août 1855, à l'occasion du jubilé accordé par Pie $\mathrm{IX}^{58}$. Une phrase, en effet, a attiré son attention et lui a paru subversive:

(...) persuadido el Papa Pio IX de que los pecados de los hombres son la causa (...) de tanto desbordamiento con que el infernal enemigo por todas partes se ostenta pretendiendo arruinar el indestructible edificio de la Santa Iglesia católica, y depravar el ánimo de todos los hombres con la dolosa extensión de la ponzoña mortal del indiferentismo e incredulidad, últimas asechanzas que ensaya para acabar con nuestra Religión santísima, y minar por su cimiento a la misma sociedad humana...

Le promotor fiscal du tribunal de Lugo, auquel il a remis la pastorale, assure que les écrits officiels des autorités constituées ne tombent pas sous le coup de la loi. Le Fiscal de la Audiencia de La Coruña est du même avis; il ne trouve d'ailleurs pas que la pastorale soit condamnable. Le gouverneur s'adresse alors au gouvemement et voudrait obtenir qu'on déplace le promotor fiscal qui ne s'est pas montré assez coopératifs'.

Ailleurs, on dénonce les prêtres qui ont fui à l'annonce du choléra, et on relève les noms de ceux qui se sont offerts pour prendre leur place afin de venir au secours des mourants ${ }^{60}$. Avoir un prêtre est important pour les habitants des villages aux portes desquels le choléra vient frapper. C'est l'assurance de recevoir l'extrême-onction et les derniers honneurs qu'accorde l'Eglise à ses fidèles. A l'archevêché de Tolède, pour n'en citer qu'un seul, arrivent des lettres d'habitants de divers bourgs qui montrent l'importance attachée à la présence d'un curé ou d'un vicaire. Ceux de San Martin de Valdeiglesias veulent garder leur curé qui a été déclaré carliste ${ }^{61}$; la municipalité de Barciense se plaint de l'ecónomo qui ne veut pas porter les secours spirituels aux cholériques ${ }^{62}$; à cette tâche par contre, le curé de Torrelaguna a laissé sa santé, comme celui d'Añover, victime de l'épidémie après s'être dépensế pour les malades et

5726 octobre 1855 (Archives du ministère de la Justice. Leg. 4042. $n^{\circ} 21826$ ).

s8 Brochure de dix pages. Lugo. imp. de Pujol y Hermano. 1855 (Archives du ministère de ta Justice. Leg. 4041).

59 lbid. Leg. 4042. Lettre du 7 septembre 1855.

* Cas du bourg de Jadar (province de Jaén). Archives du ministère de la Justice. Leg. 4040. $n^{\circ}$ 41667.

6) 30 mai 1855. Archives de l'archevêché de Tolède. LEg. Bonel y Orbe. n 9 . Año 1855.

62 Jbid. 22 octobre 1855. 
avoir même porté les morts pour les enterrer; le conseil municipal demande qu'on fasse son éloge et qu'on lui donne un remplaçant. Ce n'est pas toujours facile, beaucoup d'ecclésiastiques étant âgés ou malades et les villages nombreux et dispersés. Selon l'évêque de Calahorra, deux-cents prêtres sont morts du choléra dans son diocèse en 1855 et beaucoup d'églises restent sans prêtres au moment précis où l'on interdit les ordinations ${ }^{63}$.

Crainte du carlisme, épidémie de choléra, début de la desamortización, résistance passive des évêques et du clergé, zèle des gouverneurs civils et dénonciation auprès des autorités, cela crée un climat de fébrilité. Malgré tout, les évêques veulent se maintenir dans la légalité, la soumission au régime et engagent les ecclésiastiques à observer cette attitude.

L'oeuvre de la desamortización s'accomplit. Elle devait permettre la vente de 3123 propriétés du clergé régulier pour 49.878 . 477 réaux, et de 22.351 propriétés du clergé séculier pour 273.941.004 réaux, en l'espace d'un an et demi ${ }^{64}$. Le volume total des ventes des biens du clergé séculier est très important et dépasse celui des autres catégories. La province la plus atteinte par la désamortisation fut celle de Séville, mais en général, il y eut partout de nombreux acheteurs, l'exemple de la désamortisation de Mendizabal ayant prouvé que beaucoup s'étaient enrichis rapidement, sans inconvénient. Les scrupules existaient moins qu'en 1836. Ainsi en Vieille Castille et dans la province de León, les ventes qui alors n'avaient pas été nombreuses, se multiplièrent ${ }^{65}$.

Les propriétés vendues en 1855 furent surtout rurales, moins bien situées et de moindre qualité que celles vendues en 1836, mais leur nombre fut plus élevé.

\section{RUPTURE DES RELATIONS DIPLOMATIQUES ENTRE LE GOUVERNEMENT ESPAGNOL ET LE SAINT-SIÈGE}

La mise en oeuvre de la desamortización ne fut donc pas suspendue par la démission de Madoz et de quatre autres ministres, le 4 juin 1855 . Cette démission avait été provoquée par un décret sur la milice. Elle renforcera la position d'O'Donnell. Tenté de démissionner lui aussi, Espartero restera, sur les instances de la reine, mais il sera de plus en plus en butte aux critiques des progressistes avancés, đéçus par son peu de combativité. Le 29 juin a eu lieu le vote đéfinitif des bases de la Constitution.

\footnotetext{
63 Archives du ministère de la Justice. Leg. 4039. $\mathrm{n}^{\circ} 21506$.

G4 Renseignements fournis par la Dirección general de Bienes nacionales et publićs dans La Gaceta de Madrid du 27 février 1857. (Cité dans Simón Segura: La desamortización española del siglo XIX. Madrid. Instituto de Estudios fiscales. 1973. pp. 231-41.

(s) Ibid., p. 271.
}

La igiesia de los últimos siglos Hispania Sacra 50 (1998) 
Le nouveau cabinet ne prenant aucune mesure pour satisfaire les réclamations adressées depuis quelque temps par le chargé d'affaires du Saint-Siège, Mgr Franchi, la rupture définitive des relations diplomatiques a lieu entre le Saint-Siège et l'Espagne, le 14 juillet. Outre l'adoption de la seconde base, l'exil des évêques d'Osma et de Barcelone et la loi de desamortización, les sujets de plainte étaient nombreux, d'autres mesures anticléricales ayant été prises depuis avril: l'interdiction de conférer les ordres sacrés ${ }^{66}$, de présenter à des bénéfices ecclésiastiques ${ }^{67}$, et d'admettre des novices dans tous les monastères et couvents de femmes ${ }^{68}$. Parallèlement aux discussions sur la liberté religieuse et la desamortización, il y avait eu aux Cortès des interventions sur l'obligation que l'on devait imposer aux religieuses, soit d'enseigner, soit d'exercer une activité de bienfaisance ${ }^{69}$. Les députés les plus progressistes ne voulaient pas, en 1855, éliminer le clergé et les religieuses de l'enseignement, mais au contraire exigeaient qu'ils fissent de l'enseignement et quelque chose d'utile et d'efficace. Batllés admettait cepéndant quelques exceptions pour des êtres désabusés, désireux de se retirer du monde:

(...) aquellas personas eminentemente religiosas que, queriendo huir del bullicio de1 mundo, vayan a buscar (en los conventos) asilo y consuelo ${ }^{70}$.

Quelques jours plus tard, Caparros s'étonnait qu'on persistât à admettre des novices dans les couvents, malgré le décret du 11 septembre 1854 considérant toujours en vigueur celui du 21 juillet $1837^{71}$. Aguime précisait alors qu'il était bien dans l'intention du gouvernement de ne laisser subsister que des couvents dont l'activité fût exclusivement consacrée à l'enseignement et aux oeuvres de bienfaisance. Certains avaient habilement tourné la loi et prétextaient d'activités de bienfaisance qui ne méritaient pas ce nom, telles que le repassage du linge d'un hôpital ou la préparation de kilogrammes de charpie. Le gouvernement, conscient que l'admission à la profession religieuse devait être fonction des besoins de l'enseignement et de la bienfaisance, disait Aguirre, allait mettre fin à ces abus ${ }^{72}$. Caparros, plus tolérant lorsqu'il s'agissait de liberté de culte pour les protestants, l'engageait à fermer tous les couvents dont l'activité n'était ni utile ni rentable:

\footnotetext{
G6 Décrel du lèr avril 1855 .

67 Décret du 28 avril 1855.

68 Decret du 27 mai 1855 .

69 D.S.C.C. $\mathrm{n}^{\circ} 79$. Sčance du 8 février, p. 1317 (intervention de Batlles).

70 Ibid.

7 D.S.C.C. Tome III, n 86, pp. 1493-4.

72 lbid., p. 1495.
} 
(...) que cuanto antes se lleve a efecto esa incorporación de las monjas, suprimiendo los conventos de las otras que no estén dedicadas a instrucción y beneficencia.

Les mesures envisagées par le gouvernement sont réclamées par quelques députés démocrates ou progressistes avancés au premier rang desquels on trouve Mariano Batllés, qui se plaint de ce que des ordinations aient lieu malgré les ordres du ministère:

En Orense, un obispo ha ordenado a 48 de primeras órdenes (...) uno es un alguacil que ejercía este destino en 1854; pero era pariente o amigo de Fr. Benito Gonzalez Araujo, rector del seminario de Orense, y por razón de parentesco o amistad lo introdujo en el colegio a estudiar latín el anto pasado, y con un poco de latín, que muy poco puede ser el que sepa en tan corto tiempo, y un poco de moral, de esa que se puede decir que sólo sirve para llevar manteos, ha tenido bastante para ser ordenado con la promesa del obispo de hacerlo cura, ya in sacris en las ordenes inmediatas. Esto, señores, parece escandaloso. Que se haga curas a los hombres instruidos, a tos que han seguido una carrera, pase; pero que se haga cura a uno que era alguacil ayer, digámoslo así, y sin conocimientos para ejercer tan elevado ministerio, es una verdadera injusticia.

Il s'élève contre les simples bénéficiers, un clergé qui ne sert à rien:

Dejanđo aparte los curas y los vicarios, los demás beneficiados sólo van al coto a cantar cuatro antífonas que algunos no entienden...Son zánganos de la colmena nacional ${ }^{73}$.

Le critère de rentabilité est ici encore retenu. Pour Batllés, il faut surtout empêcher les ordinations a título de patrimonio, car ce sont des biens qui deviennent de main-morte. Dans une séance précédente, Batllés avait plaidé la cause des curés qui ont charge d'âmes et qui ne sont pour ainsi dire pas rétribués, en les opposant aux chanoines et aux évêques, trop favorisés en comparaison. Il aboutissait ainsi à la conclusion qu'il fallait au plus vite supprimer onze cathédrales, comme cela avait été décidé dans le Concordat. L'argent irait au clergé paroissial ${ }^{74}$.

Cependant, plus que ces affaires, importantes il est vrai pour Rome, qui ne considérait ni les ordinations, ni l'existence des ordres contemplatifs, en fonction de leur efficacité temporelle, ou plus exactement de leur rentabilité, c'était

73. D.S.C.C. Tome III. $\mathrm{n}^{\circ} 108$. Séance du 16 mars 1855 .

74 D.S.C.C. Tome III, pp. 1624-5. Séance du 26 février. Les circonstantes de cette rupture ont été étudiées en détail dans notre thèse: Les relations entre l'Eglise et l'Etat espagnol de 1951 à 1860. Le Concordat ef son application. Lille III, 1981, 1020 p. dactylographiés.

La iglesia de los últimos siglos

Hispania Sacra 50 (1998) 
le vote de la loi de desamortización et son début d'exécution qui avaient mené à la rupture.

Peu après la rupture, le gouvernement faisait rédiger par Cánovas del Castillo $^{75}$, une sorte de mémoire justificatif, ou Memorandum, et l'adressait à tous les gouvemements européens ${ }^{76}$ pour les convaincre du bon droit de l'Espagne dans la querelle qui l'opposait au Saint-Siège. L'argument utilisé pour atteindre ce but était l'affirmation selon laquelle la loi de desamortización ne violait pas les dispositions du Concordat.

Dans une allocution prononcée le 26 juillet, Pie IX faisait à son tour appel à l'opinion catholique et menaçait de tenir pour non avenue la clause du Concordat reconnaissant le droit de propriété de ceux qui avaient acquis des biens d'Eglise lors de la précédente desamortización.

Le gouvernement y répondit par la publication du Memorandum dans $L a$ Gaceta du 11 août et, dans celle du 21 aout, des documents relatifs aux négociations avec le Saint-Siège depuis le 1 er décembre 1854 jusqu'à cette date ${ }^{77}$.

Le 21 août également, il décréta la fermeture du Tribunal de la Rote dépendant de la Nonciature.

Le Saint-Siège attendra la fin du mois de décembre pour donner une réplique à cette publication de documents par le gouvernement. Ce seront les $O b$ servaciones de la Santa Sede al despacho del gobierno español sobre las causas de la interrupción de las relaciones recíprocas, dirigido a los representantes de la Reina en,las Cortes extranjeras con fecha 22 de julio de $1855^{78}$.

75 On connaît l'identité du rédacteur par une lettre du comte de Rayneval (Archives du ministère des Affaires étrangères de Paris: Rome. Correspondance politique. Vol. 1004, $n^{\circ} 49,15$ septembre 1855).

7622 juillet 1855 . On en a une copie dans les Archives du ministère des Affaires étrangères de Paris: Espagne. Correspondance politique. Vol. 847. Cf. réflexions de l'ambassadeur de France: 24 juillet 1855. On en trouve la minute dans les Archives du ministère des Affaires étrangères de Madrid (Negociaciones. Siglo XIX, $n^{\circ} 155$ ). Ce memoradum sera désigné seulement comme «despacho» par le cardinal Antonelli.

$n$ Documentos relativos a las negociones seguidas con la Santa Sede desde el $1^{\circ}$ de diciembre de 1854 hasta el dla. Ils furent aussi publiés sous forme de brochure. Madrid. impr. nacional. 1855. $116 \mathrm{pp}$. On trouve cette brochure notamment dans les Archives du ministère des Affaires étrangères de Paris: Espagne. Mémoires et documents. Volume 312. Le Memorandum correspond au $n^{\circ} 24$ de ces documents. pp. 100-15.

$7 \mathrm{~B}$ Comme les documents précédemment cités, ces Observaciones ont ćté publiées dans El gobierno español en sus relaciones con la Santa Sede, par CANGA ARGÜElleS, JOSÉ, Mađrid, imp. de La Regeneracion. 1856, 374 pp. (pp. 253-374). 


\section{D'OCTOBRE 1855 À JUILLET 1856. VERS LA FIN DU «BIENIO PROGRESISTA»}

La desamortización se poursuit activement; un peu grâce à elle, mais surtout grâce à l'emprunt lancé par le nouveau ministre des Finances, les caisses de l'Etat se remplissent. On va pouvoir faire face au retard de paiement des traitements des fonctionnaires et du clergé. La situation sociale reste cependant mauvaise et le choléra continue à sévir. De peur de la contagion, les députés désertent les Cortès qui ont repris leurs travaux en octobre. On met au point les derniers des 92 articles de la Constitution. Mais on observe une coupure de plus en plus nette entre l'Assemblée et le reste du pays où des troubles se produisent, et d'abord à Saragosse en raison de la cherté de la vie, puis à proximité même des Cortès avec tentative de coup d'état populaire ${ }^{79}$. C'est l'occasion d'un remaniement ministériel qui amènera au poste de ministre de la Justice, José Arias Uria ${ }^{20}$, et à celui de Gobernación, Escosura. L'influence d'O'Donnell augmente au détriment de celle d'Espartero réduit à un rôle de figurant. On oublie l'idéal progressiste et les principes révolutionnaires (qui n'avaient jamais été totalement appliqués d'ailleurs) au profit d'une politique plus conservatrice, à la grande irritation des démocrates et de tous ceux qui avaient pensé en 1854 qu'on engagerait des réformes profondes. En février, le ministre des Finances, Bruil, démissionne à la suite d'une opposition à son projet de tarifs douaniers, et son portefeuille revient à Francisco Santa Cruz qui avait été ministre de Gobemación avant juin 1855.

Le gouvernement essaye de se rapprocher de l'Eglise. On demande aux évêques d'inspirer aux Espagnols le respect de l'ordre ${ }^{81}$. Les prélats répondent aimablement en insistant sur le rôle pacificateur qu'ils entendent jouer, mais s'ils veulent bien être le meilleur auxiliaire de l'État, ils réclament la liberté pour l'exercice de leur mission et refusent toute subordination à l'autorité temporelle, ce qui ferait de l'Eglise une institution purement civile et serait sa négation même ${ }^{82}$. Cette liberté đ'action des évêques suppose celle de censurer les Jivres hérétiques ou immoraux, de pouvoir ordonner et pourvoir aux cures vacantes, d'admettre des novices à la profession religieuse, d'enseigner dans les séminaires, de faire des représentations (exposiciones) collectives et de publier celles faites à titre individuel.

798 janvier 1856.

8016 janvier 1856.

81 Circular de 6 de febrero dirigida a los Diocesanos y jurisdicciones exentas para que todo el clero se limite al modesto cumplimiento de sus deberes pastorales, sin mezclarse en luchas ni disensiones políticas (Archives du ministère de la Justice. Leg. 4036, $\mathrm{n}^{\mathrm{a}} 21506$ ). Cetle circulaire fut insếrée dans la Gaceta du 18 février.

82 Lettre de l'évêque de Gérone. 22 avril 1856 . $\mathrm{bid.}$

La iglesia de los áluimos siglos Hispania Sacra 50 (1998) 
Tous les évêques insistent sur l'indépendance de l'Église. L'évêque de Teruel ne veut pas croire qu'il puisse y avoir un plan prémédité pour soumettre l'Eglise à l'État, dit-il, cependant il semble bien qu'il le craigne:

No faltan en todas partes, hombres apasionados para quienes la fusion de la Iglesia y del Estado, de la religión y de la política, es su concepción más sublime, su bello ideal que quisieron ver realizado como la obra maestra de los progresos que han hecho entre nosotros las ciencias sociales y políticas. De esta clase de hombres habría que temer cualquier proyecto en contra de la libertad y supremacia de la Iglesia. No quieren comprender una Iglesia universal con principios inmutables e independientes de las combinaciones políticas, variables par su naturateza, y por la diferencia de tiempos y lugares...No pueden acomodarse a la idea de que haya en un estado una sola ley que no sea formada exclusivamente par la autoridad que rige y modera las cosas temporales, ni otra autoridad independiente y suprema que viva a su lado sin que le sea rival. Para ellos es una paradoja inconcebible la coexistencia de dos poderes supremos, espiritual y temporal, respetándose y auxiliándose mutuamente ${ }^{83}$.

Il n'hésile pas à dire qu'il n'y a pour l'Eglise, et selon ses principes, que deux systèmes acceptables dans les relations qu'elle doit avoir avec l'Etat: le système de séparation et le système d'alliance entre les deux, mais, concrètement, dans le cas de nations européennes, le système qui paraît normal et qui a été choissi est celui de l'alliance sur la base de Concordats. C'est le seul qu'on puisse envisager pour l'Espagne, et il faudrait révoquer les dernières ordonnances. C'est ce que demande également l'évêque de Calahorra ${ }^{84}$ en faisant remarquer que dans son diocèse, il y a eu l'année précédente deux cents décès de prêtres, et que depuis vingt-quatre ans, pas une cure n'a été pourvue: ne pourrait-on y pourvoir au fur et à mesure où parviendraient au ministère les dossiers des archiprêtrés, sans attendre le règlement paroissial définitif?

L'évêque de Vich assure aussi le gouvernement de son obéissance. Jamais il ne prêchera la rébellion ${ }^{85}$.

Alors que le danger carliste n'existe plus, le gouvernement doit réprimer des émeutes populaires dont la plus sérieuse se produit en avril, à Valence. On $\mathrm{y}$ voit la milice nationale prendre parti en faveur des insurgés. Le gouverne-ment craint ces revendications et ces révoltes d'ouvriers auxquelles s'ajoutent bientôt celles de paysans qui ont vu leur situation précaire aggravée par la

${ }^{83}$ Exposición que dirige a la reina, el obispo de Teruel, sobre la situación angustiosa de los obispos de España y la Iglesia de España. 8 de febrero de 1856 (Archives du ministère de la Justice. Leg. 4036. Dossier $n^{\circ} 21506$ ). L'évêque est Francisco Landaira y Scvilla.

84 Ibid. Leg. 4036. Dossier $n^{\circ} 21506$. On y trouve aussi la réponse de l'ćvêque de Santander. 29 février.

${ }^{85}$ rbid. 28 février 1856 . 
désamortisation ${ }^{86}$. Espartero est de moins en moins tenté par une alliance avec les démocrates. Il ne veut pas prendre le risque d'un coup d'état et continue à décevoir son propre parti.

Les lois votées par les Cortès pendant le premier semestre de 1856 , loi électorale, loi sur la presse, loi sur la milice, ont un caractère restrictif par rapport aux dispositions et aussi aux espoirs de 1854-55.

Les attaques contre ce que le régime garde d'orientations progressistes reprennent dans certains secteurs de l'opinion catholique et le journal La Regeneración entretient cet état d'esprit. Les militaires expriment aussi leur mécontentement. Bien des généraux qui avaient fait la révolution, tenus à l'écart du gouvernement, sont impatients de jouer un rôle plus actif. Quant aux investisseurs étrangers, ils sont désireux de trouver en Espagne plus de calme et de stabilité au moment où s'ouvre pour elle une ère d'expansion capitaliste.

En juin, se produisent à nouveau des émeutes, notamment en VieilleCastille, région habituellement pacifique. Le gouvernement et la majeure partie des députés y voient l'action du socialisme et s'inquiètent. La session parlementaire s'achève le premier juillet.

A la suite d'un différend avec O'Donnell, Escosura se voit obligé de démissionner. Espartero prend fait et cause pour lui, et démissionne, le 13 juillet. C'est la victoire des modérés ou des conservateurs sur les progressistes. O'Donnell se présentant en sauveur de la monarchie, dissout les Cortès et désarme la Milice nationale. Des barricades s'élèvent dans Madrid et les députés progressistes et démocrates veulent s'opposer à la dissolution de l'Assemblée, mais ils seront soumis par la force des armes. Ainsi finit le bienio progresista.

B6 TUÑón DE LARA, La España del siglo XIX, París, Librería Española, 1971, p. 158. 